\title{
XXVIII. On high electrical resistances
}

\section{J. Hopkinson F.R.S. D.Sc.}

To cite this article: J. Hopkinson F.R.S. D.Sc. (1879) XXVIII. On high electrical resistances, Philosophical Magazine Series 5, 7:42, 162-164, DOI: 10.1080/14786447908639585

To link to this article: http://dx.doi.org/10.1080/14786447908639585

$$
\text { 曲 Published online: } 13 \text { May } 2009 .
$$

Submit your article to this journal

Џ Article views: 2

Q View related articles ¿ 
A fine point of light was obtained from a fragment of a silvered bead attached to the string with wax, and illuminated by a suitably placed candle, and was observed in the direction of the length of the string through an extemporized telescope. In this way there could be no mistake as to the actual plane of vibration, or uncertainty as to the direction of the wind over the string, The path of the point of light was seen to be nearly rectilinear and vertical, showing that the vibration is across the wind. Sometimes the path was sensibly elliptic with the major axis vertical.

When a string is stretched across the slit at the bottom of a slightly open window, there is usually some difficulty in determining the actual direction of the wind where it plays upon the string. On a still night, and with a regular fire, the sound is sometimes steady for a long time, but it is wonderfully sensitive to the slightest changes in the draught. On one occasion it was found impossible to open a distant door so slightly as not to stop the sound, which would revive in a few seconds after the door was closed again. A piece of paper no larger than the hand thrown upon the fire (which was burning without flame) altered the dranght sufficiently to stop the sound until the heated air due to its combustion had passed up the chimney. It is the irregularity, and not, as has been asserted, the insufficient intensity, of the wind which prevents the satisfactory performance of the harp in the open air.

Terling Place, Witham,

Feb. 8, 1879.

XXVIII. On High Electrical Resistances.

By J. Hopkinson, F.R.S., D.Sc.*

TN the Philosophical Magazine of July 1870 Mr. Phillips 1 describes a method of readily constructing very high electrical resistances. A pencil-line is ruled on glass; the ends of the line are provided with the means of making electrical connexion; and the whole is varnished: by this means a resistance of two million ohms was obtained; and it was found to be constant under varying potential. This method of constructing resistances is alluded to in Maxwell's 'Electricity' (p. 392); but I do not know that it has received the examination it deserves, or that it has come into general use. Having need of resistances of over 100 million ohms, I have made a few on Mr. Phillips's plan, ranging from 26,000 ohms to $96,000,000 \mathrm{ohms}$ (which are fairly satisfactory), and one or two

* Communicated by the Author. 
much greater (which do not conduct according to Ohm's law, but with a resistance diminishing as the electromotive force increases). A short description of these may perhaps save a little trouble to others who desire tolerably constant high resistances.

All my resistances are ruled on strips of patent plate glass which has been finished with fine emery, but has not been polished. The strips are twelve inches long, and, except in the cases specified below, about half an inch wide. One or more parallel lines are ruled on each strip, terminating at either end in a small area covered with graphite from the pencil. The strip of glass, first heated over a spirit-lamp, is varuished with shellac varnish, excepting only these small terminal areas, which are surrounded by a small cup of paraffin-wax to contain mercury to make the necessary connexions. To secure better insulation, feet of paraffin or of glass covered with paraffin are attached on the underside at the ends of the strip to support it from the table. Before varnishing, each strip was marked with a distinguishing letter. The strips marked $g, h, i, a$, and $b$ were ruled with a $\mathrm{BB}$ pencil, the remainder with a $\mathrm{HHH}$.

These resistances appear to be not quite constant, but to vary slightly with time, the maximum variation in four months being slightly in excess of $\frac{1}{2}$ per cent. In every case they were examined under varying potential to ascertain if they obeyed Ohm's law. With the exception of $f$, described below, all were satisfactory in this respect. The resistance appears to diminish slightly as the temperature rises; but this conclusion rests on a single rough experiment, and must be regarded as uncertain.

The values of the resistances were determined with a differential galvanometer, each coil having a resistance of 3500 ohms, by the well-known method of dividing a battery-current, passing one part through the large resistance to be measured and one coil of the galvanometer, the other through a set of coils or other known resistance, and then through the galvanometer shunted with a second set of resistance-coils. $g$ was thus compared with standard coils. $g$ was then used to find $h$ and $i$; and $h+i$ was used to find $a$ and $b$. A Thomson's quadrant electrometer was used to compare in succession $k, l$, and $m$ with $a+b . \quad c$ and $e$ were similarly compared with $k+l+n$; and, lastly, $c$ and $e$ were used to examine $f$.

$g$ is ruled on a strip one inch wide, rather more than half the surface being covered with graphite. Three experiments on the same day gave $26,477,26,461$, and $26,470 \mathrm{ohms}$; the variations are probably due to uncertainty in the temperaturecorrection, the galvanometer-coils being of copper. After the lapse of four months $26,615 \mathrm{ohms}$ was obtained.

$i$ is ruled on a strip three quarters of an inch wide, with nine 
tolerably strong lines; its resistance was first found to be 209,907 ohms, and four months later to be 208,840 .

$b$ has four strong lines on a strip half an inch wide; resistance 207,954 on a first occasion, and 208,750 after the lapse of four months.

$a$ has two lines narrower than the preceding; resistance $5,240,000$ at first, and 5,220,800 after four months.

$h$ has a single line apparently similar to either of those of $a$; and the resistance is $9,168,000$.

$k, l$, and $m$ have each two lines ruled with a $\mathrm{HHH}$ pencil; their resistances are respectively $23,024,000,14,400,000$, and $13,218,000$ ohms.

$c$ and $e$ also hare two lines, but they are finer; the resistances are 79,407,000 and 96,270,000.

As already mentioned, all the preceding were tested with various battery-power, and were found to obey $\mathrm{Ohm}$ 's law within the limits of observation. It was not so with $f$, as the following observation shows very clearly. $c, k, e$, and $f$ were arranged as a Wheatstone's bridge. Junctions $(f, c)$ and $(e, k)$ were connected to the poles of a Daniell's battery varying from one to eighteen elements; junctions $(e, f)$ and $(k, c)$ were respectively connected through the reversing-key with the quadrants of the electrometer. The potential of one Daniell's element was represented by 270 divisions of the scale of the electrometer. Column I. gives the number of elements employed, II. the corresponding reading of the electrometer, III. the value of $\frac{k}{k+c}-\frac{e}{f+e}$ deduced therefrom, and IV. the values of the ratio resistance of $f$ : resistance of $e$.

$\begin{array}{rccc}\text { I. } & \text { II. } & \text { III. } & \text { IV. } \\ 1 & 16 & 0 \cdot 060 & 5 \cdot 1 \\ 2 & 25 & 0 \cdot 046 & 4 \cdot 6 \\ 3 & 31 \frac{1}{2} & 0 \cdot 039 & 4 \cdot 4 \\ 4 & 31 & 0 \cdot 029 & 4 \cdot 1 \\ 5 & 28 & 0 \cdot 021 & 3 \cdot 9 \\ 6 & 27 \frac{1}{2} & 0 \cdot 017 & 3 \cdot 8 \\ 9 & 10 & 0 \cdot 0041 & 3 \cdot 5 \\ 12 & -5 & -0 \cdot 0016 & 3 \cdot 4 \\ 15 & -25 & -0 \cdot 006 & 3 \cdot 3 \\ 18 & -47 & -0 \cdot 0097 & 3 \cdot 25\end{array}$

This result is by no means surprising. There is doubtless an exceedingly minute discontinuity in the fine line across which disruptive discharge occurs; and the moral is, that resistances of this kind should always be tested as regards their behaviour under varying electromotive force.

Several attempts to rule a line on a strip 12 inches long with a resistance over $100,000,000$ ohms resulted in failure. 